\title{
Ecophysiological modeling of photosynthesis and carbon allocation to the tree stem in the boreal forest
}

\author{
Fabio Gennaretti ${ }^{1, \text { a }}$, Guillermo Gea-Izquierdo ${ }^{2}$, Etienne Boucher ${ }^{3}$, Frank Berninger ${ }^{4}$, Dominique Arseneault ${ }^{5}$, and \\ Joel Guiot ${ }^{1}$ \\ ${ }^{1}$ CEREGE, Aix-Marseille University, CNRS, IRD, Aix en Provence, 13545, France \\ ${ }^{2}$ Departamento de Sistemas y Recursos Forestales, CIFOR-INIA, Madrid, 28040, Spain \\ ${ }^{3}$ Département de géographie, Université du Québec à Montréal, Montréal, H3C3P8, Canada \\ ${ }^{4}$ Department of Forest Sciences, University of Helsinki, Helsinki, 00014, Finland \\ ${ }^{5}$ Département de biologie, chimie et géographie, Université du Québec à Rimouski, Rimouski, G5L3A1, Canada \\ anow at: INRA Centre Grand Est - Nancy, UMR1137 Ecologie et Ecophysiologie Forestières, Champenoux, 54280, France
}

Correspondence to: Fabio Gennaretti (fabio.gennaretti@inra.fr)

Received: 19 February 2017 - Discussion started: 23 February 2017

Revised: 19 September 2017 - Accepted: 27 September 2017 - Published: 6 November 2017

\begin{abstract}
A better understanding of the coupling between photosynthesis and carbon allocation in the boreal forest, together with its associated environmental factors and mechanistic rules, is crucial to accurately predict boreal forest carbon stocks and fluxes, which are significant components of the global carbon budget. Here, we adapted the MAIDEN ecophysiological forest model to consider important processes for boreal tree species, such as nonlinear acclimation of photosynthesis to temperature changes, canopy development as a function of previous-year climate variables influencing bud formation and the temperature dependence of carbon partition in summer. We tested these modifications in the eastern Canadian taiga using black spruce (Picea mariana (Mill.) B.S.P.) gross primary production and ring width data. MAIDEN explains $90 \%$ of the observed daily gross primary production variability, $73 \%$ of the annual ring width variability and $20-30 \%$ of its high-frequency component (i.e., when decadal trends are removed). The positive effect on stem growth due to climate warming over the last several decades is well captured by the model. In addition, we illustrate how we improve the model with each introduced model adaptation and compare the model results with those of linear response functions. Our results demonstrate that MAIDEN simulates robust relationships with the most important climate variables (those detected by classical response-function analysis) and is a powerful tool for understanding how environmental factors interact with black spruce ecophysiol-
\end{abstract}

ogy to influence present-day and future boreal forest carbon fluxes.

\section{Introduction}

Photosynthetic production is the primary factor affecting growth of trees and other vegetation. However, empirical studies have shown that the correlation between photosynthetic production and the diameter growth of trees is far from perfect (Gea-Izquierdo et al., 2014; Rocha et al., 2006; Berninger et al., 2004). This imperfect correlation is due to the fact that plant hydraulics (e.g., turgor pressure) and thermal limitations during very short periods of time can be more important than carbon (C) availability for secondary tree growth (Kirdyanov et al., 2003; Rossi et al., 2016; Zweifel et al., 2016; Fatichi et al., 2014; secondary growth is the increase in the girth of the plant roots and stems). These factors influence the proportion of net primary productivity allocated to stem growth each year, dampening the correlation between gross primary production (GPP) and growth. A better understanding of these factors and of carbon allocation mechanisms is needed when studying forest dynamics, forest carbon balance and the impact of climate change on forests. Carbon allocated in different tree components (e.g., canopy, stem or roots) has a specific function and is stored for a different length of time (Moorcroft, 2006). 
The varying roles of allocation and photosynthetic production are integrated in ecophysiological models ( $\mathrm{Li}$ et al., 2014). Such models are important tools for analyzing the direct influence of climate and other environmental factors (e.g., $\mathrm{CO}_{2}$ concentration) on tree growth and biogeochemical processes in forest ecosystems ( $\mathrm{Li}$ et al., 2016). Climategrowth relationships have traditionally been assessed using empirical response functions based on linear relationships, thus considering the underlying processes as a black box. In contrast, ecophysiological models are built on mechanistic rules and allow for consideration of non-stationarity and nonlinearity in tree responses to environmental variables as well as their interactions (Vaganov et al., 2006). Ecophysiological models may be refined using model-data fusion approaches and optimization techniques (Guiot et al., 2014).

Different models with a different degree of ecophysiological complexity and/or spatiotemporal resolution have already been used to investigate the influence of climate and weather on tree growth in the boreal forest. Some studies focused on the drivers of photosynthetic capacity. For example, Mäkelä et al. (2004) proposed a model to study the influence of temperature on the seasonal variation in photosynthetic production of Scots pine through a delayed dynamic response. Other studies focused on the drivers of carbon allocation. For example, in Manitoba, Canada, a model related GPP and carbon allocation to absorbed photosynthetically active radiation as a function of environmental constraints (Girardin et al., 2008). Another model, called CASSIA (Schiestl-Aalto et al., 2015), was developed to investigate how environmental factors and the ontogenetic stage of tree development influence the annual course of carbon sink-source dynamics in Scots pine stands. However, despite recent progress, few models have been able to simultaneously simulate the meteorological control on daily photosynthetic production and the meteorological and phenological controls on daily carbon allocation for temperature-limited boreal forest ecosystems. Such models should be able to simulate the following observed phenomena: (i) the delayed response of photosynthesis to temperature (Gea-Izquierdo et al., 2010; Mäkelä et al., 2004), (ii) the influence of preceding season conditions on current-year canopy development (Salminen and Jalkanen, 2005) and (iii) a strong positive relationship between wood biomass production and temperature (Cuny et al., 2015).

Here, we try to fill this gap by adapting the MAIDEN forest ecophysiological model, developed for temperate and Mediterranean environments (Misson, 2004; Gea-Izquierdo et al., 2015), to mimic how weather and climate influence photosynthesis, phenology and carbon allocation in the North American boreal forest on a daily basis. MAIDEN offers an ideal framework to analyze the impact of introducing relevant processes for carbon assimilation and allocation in temperature-sensitive boreal trees into the model. Indeed, the model simultaneously simulates the course of photosynthesis and sets different phenological phases to determine the allocation of carbon to different plant compart- ments in a dynamic manner. In this study, we first test and optimize new model features on GPP and growth data from black spruce (Picea mariana (Mill.) B.S.P.), the dominant tree species across the North American boreal biome. Second, we show the impact of single processes in the model runs and the improvements achieved with the new model adaptations. Last, we compare the simulated GPP and stem growth results with those obtained with conventional empirical linear response functions. This comparison allows us to verify that the process-based ecophysiological model satisfactorily reproduces the variability in the observed data and that its simulations keep robust relationships with the most significant climate variables.

\section{Materials and methods}

\subsection{The MAIDEN model}

MAIDEN (Misson, 2004; Gea-Izquierdo et al., 2015) can consider the influence of several environmental factors on forest water and carbon cycles. Starting from daily minimum-maximum air temperature, precipitation and $\mathrm{CO}_{2}$ atmospheric concentration (these are the minimum required input variables; radiation, relative humidity and wind speed are included when additional meteorological data are available; Misson, 2004), MAIDEN models the phenological and meteorological controls on GPP and carbon allocation (Fig. 1; see also flowcharts in Misson, 2004, and GeaIzquierdo et al., 2015). The model explicitly allocates carbon to different pools (storage, canopy, roots and stem) on a daily basis using phenology-dependent mechanistic rules. The model has already been successfully optimized for Quercus petraea (Matt.) Liebl. and 12 Mediterranean species, including several Pinus spp. and Quercus spp. (Gaucherel et al., 2008a, b; Danis et al., 2012; Misson, 2004; Misson et al., 2004; Boucher et al., 2014; Gea-Izquierdo et al., 2015, 2017). Thus far, the model has never been used to simulate forest growth under boreal conditions.

MAIDEN requires the definition of species- and sitedependent parameters (Misson, 2004; Gea-Izquierdo et al., 2015), such as soil texture and depth and the root-to-leaf mass fraction in the studied trees. The parameters that could not be set for the studied black spruce sites were analyzed with sensitivity analysis, and the most influential of them were estimated with Bayesian optimization algorithms (Robert, 1996) using observed time series (daily GPP and annual ring width) as a reference. In total, 6 parameters influencing the GPP for black spruce and 12 parameters controlling the carbon allocation to the stem (Dstem) were optimized (they are described in the following paragraphs and in Table 1). The optimization was based on Markov chain Monte Carlo (MCMC) sampling, which, through its iterations, only retains combinations of parameters satisfying some conditions (Supplement S1; Fig. S1 in the Supple- 


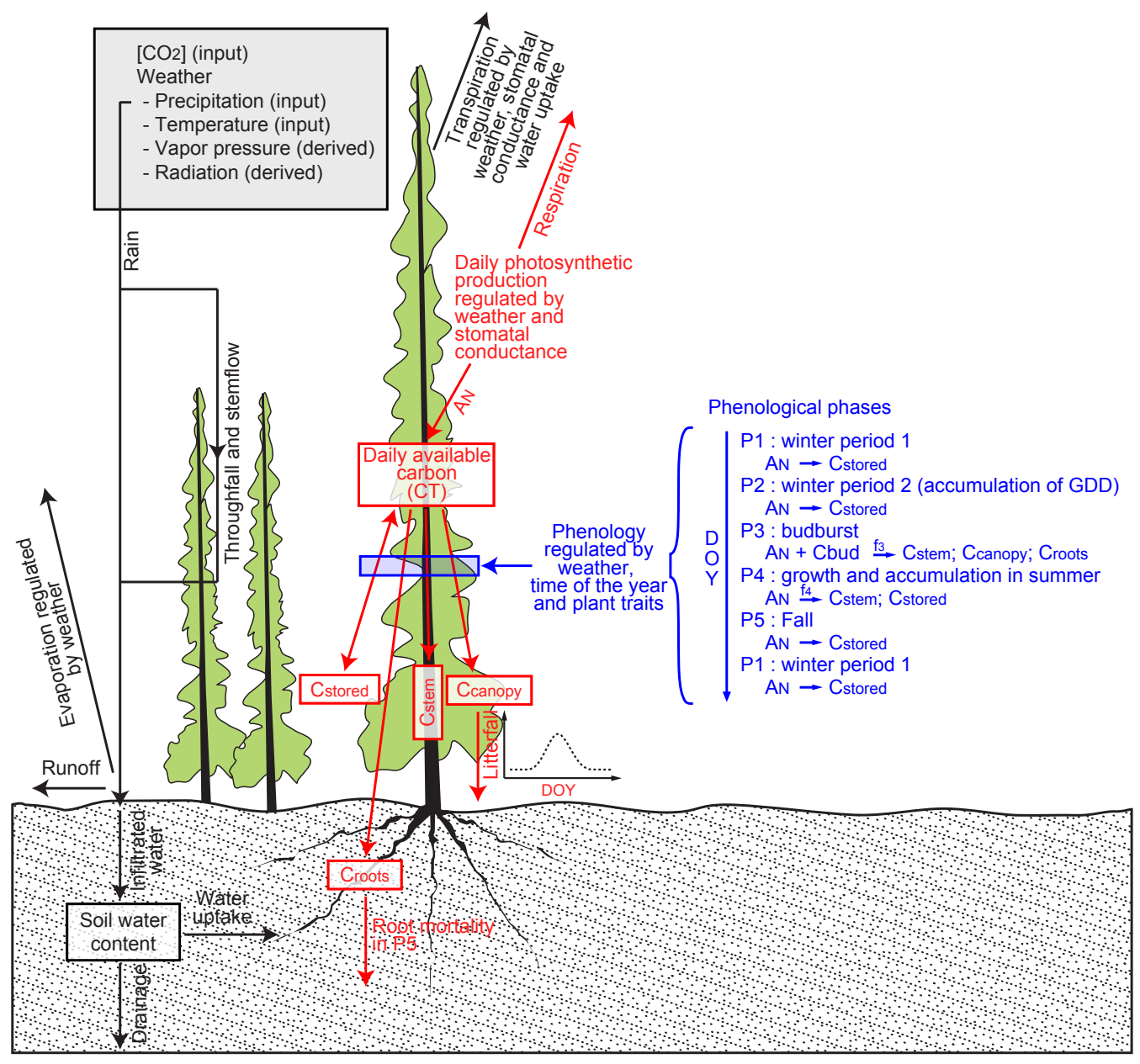

Figure 1. MAIDEN-simulated phenology (blue), water (black) and carbon (red) fluxes. AN: net photosynthesis corresponding to net primary production. Cstored, Cstem, Ccanopy and Croots: carbon allocated daily to stored non-structural carbohydrates, stem, canopy and roots, respectively. DOY: day of the year (1-365). GDD: growing degree days. $f_{3}$ and $f_{4}$ : functions determining carbon allocation in phases 3 and 4. Cbud: amount of storage carbon that is used each day by the plant in phase 3 .

ment). Among the retained blocks of parameters, one block of six parameters controlling GPP ("plausible block GPP") and one block of 12 parameters controlling Dstem ("plausible block stem") were selected to illustrate the results with likely parameter values (Supplement S1). The robustness of the parameters' posterior distributions was tested on a crossvalidation exercise (Supplement S1).

\subsubsection{Modeling the GPP of boreal forests}

In MAIDEN, the daily stand GPP $\left(\mathrm{g} \mathrm{C} \mathrm{m}^{-2} \mathrm{day}^{-1}\right)$ is derived from the modeling of the coupled photosynthesis-stomatal conductance system. Leaf photosynthesis is calculated following De Pury and Farquhar (1997), while stomatal conductance is estimated using a modified version of the Leuning equation (Leuning, 1995; Gea-Izquierdo et al., 2015). The photosynthesis-stomatal conductance system is estimated separately for sun and shade leaves based on the photosyn- thetic photon flux density they receive. The partition of leaf area index (LAI) in its shaded and sunlit fractions and the transmission and absorption of photosynthetically active radiation (PAR) are computed as explained by Misson (2004), following De Pury and Farquhar (1997). After a sensitivity analysis, and as stated in the literature for boreal forests (Gea-Izquierdo et al., 2010; Mäkelä et al., 2004, 1996), we found that the modeling of assimilation/photosynthesis for black spruce is very sensitive to the parameters controlling the temperature dependence of the maximum carboxylation rate $\left(\mathrm{Vcmax} ; \mu \mathrm{mol} \mathrm{C} \mathrm{m}{ }^{-2}\right.$ of leaves $\mathrm{s}^{-1}$ ), the water stress level $(\theta g)$ influencing the stomatal conductance and consequently the intercellular $\mathrm{CO}_{2}$ concentration. The computations of Vcmax and $\theta g$ used here are identical to those of the prior formulation of MAIDEN (Gea-Izquierdo et al., 2015). The Vcmax is modeled as follows:

$\mathrm{Vcmax}_{i}=\frac{\mathrm{Vmax}}{1+\exp \left(\mathrm{Vb} \cdot\left(\mathrm{Tday}_{i}-\mathrm{Vip}\right)\right)}$. 
Table 1. Definitions, symbols and prior and posterior ranges of calibrated parameters. Small posterior ranges relative to the prior ones indicate sensitive parameters.

\begin{tabular}{|c|c|c|c|c|c|c|c|}
\hline $\begin{array}{l}\text { Overall } \\
\text { process }\end{array}$ & Specific process & Eq. & Parameter & Meaning & Units & Prior range & $\begin{array}{l}\text { Posterior range } \\
\text { (value in plausible } \\
\text { block) }\end{array}$ \\
\hline \multirow[t]{6}{*}{ GPP } & $\begin{array}{l}\text { temperature dependence } \\
\text { of Vcmax }\end{array}$ & 1 & Vmax & $\begin{array}{l}\text { asymptote/maximum } \\
\text { value }\end{array}$ & $\begin{array}{l}\mu \mathrm{mol} \mathrm{Cm^{-2 }} \text { of } \\
\text { leaves s}^{-1}\end{array}$ & $5 / 150$ & $39 / 67(45)$ \\
\hline & $\begin{array}{l}\text { temperature dependence } \\
\text { of } \mathrm{V} \text { cmax }\end{array}$ & 1 & $\mathrm{Vb}$ & slope & $\mathrm{n} / \mathrm{a}$ & $-0.30 /-0.10$ & $\begin{array}{l}-0.21 /-0.17 \\
(-0.20)\end{array}$ \\
\hline & $\begin{array}{l}\text { temperature dependence } \\
\text { of } \mathrm{V}_{\text {cmax }}\end{array}$ & 1 & Vip & inflection point & ${ }^{\circ} \mathrm{C}$ & $10 / 30$ & $17.5 / 22.3(18.8)$ \\
\hline & $\begin{array}{l}\text { water stress level influ- } \\
\text { encing the stomatal con- } \\
\text { ductance }\end{array}$ & 2 & soilb & slope & $\mathrm{n} / \mathrm{a}$ & $-0.025 /-0.005$ & $\begin{array}{l}-0.023 /-0.008 \\
(-0.012)\end{array}$ \\
\hline & $\begin{array}{l}\text { water stress level influ- } \\
\text { encing the stomatal con- } \\
\text { ductance }\end{array}$ & 2 & soilip & inflection point & $\mathrm{mm}$ & $100 / 400$ & 102/193 (129) \\
\hline & $\begin{array}{l}\text { acclimation to tempera- } \\
\text { ture of photosynthesis }\end{array}$ & 3 & $\tau$ & needed days & days & $1 / 20$ & 11.6/13.7 (12.4) \\
\hline \multirow{12}{*}{$\begin{array}{l}\text { C alloca- } \\
\text { tion to } \\
\text { stem }\end{array}$} & $\begin{array}{l}\text { definition of canopy max- } \\
\text { imum amount of } C\end{array}$ & 4 & CanopyT & $\begin{array}{l}\text { slope of the temperature } \\
\text { dependence }\end{array}$ & $\mathrm{n} / \mathrm{a}$ & $0 / 20$ & $0.54 / 19.24(6.87)$ \\
\hline & $\begin{array}{l}\text { definition of canopy max- } \\
\text { imum amount of } C\end{array}$ & 4 & CanopyP & $\begin{array}{l}\text { slope of the precipitation } \\
\text { dependence }\end{array}$ & $\mathrm{n} / \mathrm{a}$ & $0 / 20$ & $1.70 / 19.85$ (16.68) \\
\hline & $\begin{array}{l}\text { start of growing season } \\
\text { (budburst) }\end{array}$ & NA & GDD1 & GDD sum threshold & ${ }^{\circ} \mathrm{C}$ & $10 / 120$ & $56.75 / 87.05(70.22)$ \\
\hline & $\begin{array}{l}\text { start of growing season } \\
\text { (budburst) }\end{array}$ & NA & vegphase 23 & day before the later start & day of the year & $152 / 181$ & $161.5 / 171.0(167.0)$ \\
\hline & $\begin{array}{l}\text { start of growing season } \\
\text { (budburst) }\end{array}$ & NA & day23_flex & $\begin{array}{l}\text { acclimation to changing } \\
\text { GDD sums }\end{array}$ & years & $1 / 10$ & $1.53 / 3.29(2.24)$ \\
\hline & $\begin{array}{l}\text { daily available } \mathrm{C} \text { in } \\
\text { phase } 3\end{array}$ & NA & Cbud & $\begin{array}{l}\text { storage } \mathrm{C} \text { used by the } \\
\text { plant }\end{array}$ & $\begin{array}{l}\mathrm{g} \mathrm{C} \mathrm{m}^{-2} \text { of } \\
\text { stand day }\end{array}$ & $1 / 3$ & $1.59 / 1.86(1.69)$ \\
\hline & partition of $\mathrm{C}$ in phase 3 & 5 & $h_{3}$ & $\begin{array}{l}\text { portion allocated to } \\
\text { canopy and roots }\end{array}$ & fraction $(0-1)$ & $0 / 1$ & $0.983 / 1.000(0.991)$ \\
\hline & $\begin{array}{l}\text { partition of } \mathrm{C} \text { in phase } 4 \\
\text { (stem versus storage) }\end{array}$ & 6 & st4temp & $\begin{array}{l}\text { inflection point of the } \\
\text { temperature dependence }\end{array}$ & ${ }^{\circ} \mathrm{C}$ & $1 / 100$ & $27.53 / 59.11(46.78)$ \\
\hline & $\begin{array}{l}\text { transition from phase } 4 \\
\text { to } 5\end{array}$ & NA & photoper & photoperiod threshold & hours & $12 / 14$ & $12.96 / 13.72(13.41)$ \\
\hline & C losses from the canopy & 7 & PercentFall & $\begin{array}{l}\text { yearly canopy turnover } \\
\text { rate }\end{array}$ & fraction $(0-1)$ & $0.09 / 0.15$ & $0.093 / 0.149(0.143)$ \\
\hline & C losses from the canopy & 7 & OutMax & $\begin{array}{l}\text { approximate day of the } \\
\text { year with maximum } \\
\text { losses }\end{array}$ & day of the year & $150 / 200$ & $154.2 / 195.0(171.7)$ \\
\hline & C losses from the canopy & 7 & OutLength & $\begin{array}{l}\text { index proportional to the } \\
\text { length of the period with } \\
\text { losses }\end{array}$ & $\mathrm{n} / \mathrm{a}$ & $4 / 12$ & $4.80 / 10.80(9.91)$ \\
\hline
\end{tabular}

Vcmax is a logistic function determining how daytime temperature $\left(\right.$ Tday; ${ }^{\circ} \mathrm{C}$ ) controls the maximum carboxylation rate at day $i$ if Rubisco is saturated. The parameters Vmax, $\mathrm{Vb}$ and $\mathrm{Vip}$ are the asymptote, the slope and the inflection point of $\mathrm{Vcmax}_{i}$, respectively. In the model, temperature dependence when photosynthesis is limited by electron transport (Jmax) is considered linearly related to Vcmax.

The $\theta g$ influencing stomatal conductance is modeled as follows:

$\theta g_{i}=\frac{1}{1+\exp \left(\mathrm{soilb} \cdot\left(\mathrm{SWC}_{i}-\text { soilip }\right)\right)}$.

$\theta g$ is a logistic function that varies from 0 (maximum stress) to 1 (no stress) at day $i$ depending on the soil water content
(SWC; $\mathrm{mm}$ ). soilb and soilip are the slope and the inflection point of $\theta g_{i}$, respectively.

With its already published MAIDEN configuration (GeaIzquierdo et al., 2015), the model overestimated black spruce GPP in spring. This overestimation is due to the fact that the model has been developed for temperate and Mediterranean trees where no time delay between the recovery of photosynthesis and temperature increase in spring (i.e., no temperature acclimation) can be assumed. However, such a delay is common in boreal trees (Gea-Izquierdo et al., 2010; Mäkelä et al., 2004). For this reason, we modified MAIDEN by including an extra function and an extra parameter $(\tau)$ to take into account the acclimation of photosynthesis to temperature. We replaced Tday in Eq. (1) by a temperature transformation $(S)$, 
which responds smoothly with a determined time lag to temperature variations. $S$ of day $i$ was computed from the following differential equation (Mäkelä et al., 2004), which was solved with Euler's method:

$\frac{\mathrm{d} S_{i}}{\mathrm{~d} i}=\frac{\mathrm{Tday}_{i}-S_{i}}{\tau}$.

The new parameter $\tau$ is a time constant interpretable as the number of days needed by the photosynthetic apparatus to acclimate to changing temperature.

\subsubsection{Modeling carbon allocation to the stem (Dstem) in boreal forests}

MAIDEN allocates the daily available carbon from photosynthesis and stored non-structural carbohydrates to all plant compartments (stem, roots, canopy and storage) using functional rules specific to each of the five phenological phases characterizing a year (see Fig. 1). Although we maintained the original MAIDEN structure, we modified some previously used functional rules from Gea-Izquierdo et al. (2015) to consider significant processes for the boreal forest. Below, we describe the functional rules controlling Dstem according to phenological phases.

During "winter period 1" (phase 1), few processes are active. However, at the beginning of each year, the model defines the maximum amount of carbon that the canopy can potentially contain that year (AlloCcanopy ${ }_{j} ; \mathrm{g} \mathrm{C} \mathrm{m}^{-2}$ of stand) as a function of previous-year climate variables. Based on previous studies on black spruce forests (Girardin et al., 2016; Ols et al., 2016; Mamet and Kershaw, 2011), we modified the model to consider the effect of the previous-year April precipitation and July-August temperature that likely influence the length and the thermal-hydraulic stress of the previous growing season, respectively. Previous-year climate conditions of specific months are known to influence the shoot extension of boreal trees likely because they control the accumulation of resources in the buds (Salminen and Jalkanen, 2005). Here, we calculated the carbon potentially allocated each year to the canopy with the following equations:

$$
\begin{gathered}
\text { CanopyMult }=\frac{1}{1+\exp \left(\text { CanopyT } \cdot \text { Temp }_{j-1}\right)} \\
\cdot \frac{1}{1+\exp \left(\text { CanopyP } \cdot \text { Precip }_{j-1}\right)}
\end{gathered}
$$

AlloCcanopy $_{j}=0.7 \cdot$ MaxCcanopy +0.3

$$
\text { · MaxCcanopy · CanopyMult, }
$$

where Temp ${ }_{j-1}$ is the previous-year mean July-August temperature (detrended and transformed to $z$ scores), Precip ${ }_{j-1}$ is the previous-year April precipitation (detrended and transformed to $z$ scores) and MaxCcanopy is the absolute maximum canopy carbon reservoir determined based on forest traits, diameter distributions and previously published allometric equations (Chen, 1996; Bond-Lamberty et al., 2002a, b). CanopyT and CanopyP are two parameters that were optimized and represent the slopes of the relationships between CanopyMult (i.e., the overall climate dependence) and Temp ${ }_{j-1}$ or Precip ${ }_{j-1}$, respectively. In this way, AlloCcanopy $_{j}$ may vary between 70 and $100 \%$ of MaxCcanopy, as in the previous version of the model (GeaIzquierdo et al., 2015).

During "winter period 2" (phase 2), growing degree days (GDD) start to accumulate. We computed the accumulation of GDD by summing the mean daily temperature values over $3^{\circ} \mathrm{C}$ (Nitschke and Innes, 2008; Man and Lu, 2010). MAIDEN simulates budburst (i.e., the transition from phenological phase 2 to 3) either when the GDD sum threshold is reached (parameter GDD1) or when a selected day of the year related to photoperiod is passed (parameter vegphase23). With this model configuration, the start of the growing season overreacted to GDD yearly variations. To correct for this simulated bias, we modified MAIDEN by adding a mechanism reducing the interannual variability of budburst dates. This mechanism simulates the acclimation of the plants to varying GDD sums from year to year. The yearly time series of days of the year corresponding to budburst (determined by GDD and photoperiod) is smoothed at the beginning of each simulation with an $n$-year cubic smoothing spline. The integer number $n$ was called day 23 _flex and optimized similar to the other parameters.

The "budburst phase" (phase 3) starts with budburst and ends when AlloCcanopy ${ }_{j}$ is reached or when the carbon in the storage reservoir (i.e., stored non-structural carbohydrates) is lower than a minimum value (Misson, 2004). This phase was set to be shorter than 51 days based on available spruce budburst and shoot elongation data (Lemieux, 2010). During this phase, the daily available carbon $\left(\mathrm{CT}_{i}\right)$ comes from photosynthesis and the mobilization of storage carbon. The parameter Cbud, which was optimized, is the amount of storage carbon that is used each day by the plant. The total $\mathrm{CT}_{i}$ amount is then allocated to the canopy, the roots or the stem following some functional rules. In the previous version of MAIDEN (Gea-Izquierdo et al., 2015), these rules were functions of daily soil moisture and air temperature. In this case, these rules did not improve the simulated results, and we retained a simpler version independent of the climate:

$\mathrm{Cstem}_{i}=\mathrm{CT}_{i} \cdot\left(1-h_{3}\right)$,

where $\mathrm{Cstem}_{i}$ is the portion of $\mathrm{CT}_{i}$ allocated to stem and $h_{3}$ is a parameter to be defined in the range between 0 and 1 . The rest of $\mathrm{CT}_{i}$ is allocated to the canopy or the roots, with a prescribed 1.65 root-to-canopy mass ratio for black spruce (Czapowskyj et al., 1985; Jenkins et al., 2003).

During the "growth and accumulation phase in summer" (phase 4), $\mathrm{CT}_{i}$ comes from only photosynthesis and is allocated either to stem growth or to storage as a function of climate forcing. For water-limited sites in the previous version of MAIDEN (Gea-Izquierdo et al., 2015), the allocation rule used a combination of daily soil moisture and air temperature 
as predictors. In this case, for temperature-limited sites, we used only temperature and set soil moisture at null (i.e., always equal to 1 ; note that for more water-limited boreal sites, this water stress dependence can be used):

$$
\operatorname{Cstem}_{i}=\mathrm{CT}_{i} \cdot\left(1-0.8 \cdot \exp \left(-0.5\left(\frac{\operatorname{Tmax}_{i}}{\mathrm{st} 4 \text { temp }}\right)^{2}\right)\right)
$$

where $\operatorname{Tmax}_{i}$ is the daily maximum temperature and st4temp is a parameter that corresponds to the inflection point of the function. The value 0.8 was chosen to force a minimum threshold of $\mathrm{C}$ allocation to the stem in this phase (at least $20 \%$ ) and to guarantee the correspondence between the inflection point and the temperature where approximately $50 \%$ of $\mathrm{CT}_{i}$ is allocated to the stem.

The transition from phase 4 to the "fall phase" (phase 5) is determined by either the parameter photoper (threshold of duration of daylight in hours) or by the occurrence of negative minimum daily temperature values after 1 September. During the "fall phase", all photosynthetic products are allocated to the storage reservoir, and mortality of fine roots occurs. No specific functional rule influences Dstem during this phase.

The equation controlling partial carbon losses from the canopy (i.e., litterfall), which influences the photosynthetic capacity through modifications of the total leaf area in the studied evergreen species, runs all year round. This equation is adapted from Maseyk et al. (2008):

$$
\begin{aligned}
& \text { outCcanopy }_{i}=\left(\text { PercentFall } \cdot \text { AlloCcanopy }_{j}\right) \\
& \cdot \exp \left(-0.5\left(\frac{\text { DOY }_{i}-1}{\text { OutMax }}\right)^{\text {OutLength }}\right)
\end{aligned}
$$

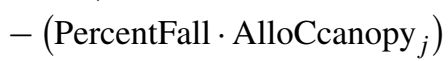

$$
\begin{aligned}
& \cdot \exp \left(-0.5\left(\frac{\mathrm{DOY}_{i}}{\text { OutMax }}\right)^{\text {OutLength }}\right) \text {, }
\end{aligned}
$$

where outCcanopy $i$ is the carbon loss from the canopy at day $i$ and is influenced by parameters PercentFall, OutMax and OutLength (to be optimized), which determine the yearly canopy turnover rate, the day of the year with maximum losses and the length of the period with losses, respectively.

\subsubsection{Model evaluation}

The proportion of the observed variability explained by MAIDEN was evaluated with the coefficient of determination $\left(R^{2}\right)$, which compares the performance of simulated time series relative to that of straight horizontal lines centered on the data:

$R^{2}=1-\frac{\sum_{i}\left(\mathrm{Obs}_{i}-\mathrm{Sim}_{i}\right)^{2}}{\sum_{i}\left(\mathrm{Obs}_{i}-\overline{\mathrm{Obs}}\right)^{2}}$.

\subsection{Study sites and data}

\subsubsection{Eddy covariance observations}

We used daily GPP data from one eddy covariance station located in a mature black spruce forest in the northern Quebec taiga ("Quebec Eastern Old Black Spruce" station - EOBS; $49.69^{\circ} \mathrm{N}, 74.34^{\circ} \mathrm{W}$; data from 2003 to 2010; Bergeron et al., 2007; http://fluxnet.ornl.gov/site/269; additional information in Supplement S2 and Fig. S2) to optimize the six parameters influencing stand GPP simulated by MAIDEN for the studied species.

\subsubsection{Ring width data from the northern Quebec taiga}

We assumed that the yearly Dstem is proportional to tree-ring growth to use ring width data to optimize MAIDEN (12 influential parameters). A regional chronology (RW) and a detrended regional chronology (RWhighF) were obtained from 46 black spruce trees sampled in the riparian forests of five lakes in the eastern Canadian taiga (Gennaretti et al., 2014; the coordinates of the central point are $54.26^{\circ} \mathrm{N}, 71.34^{\circ} \mathrm{W}$; see Fig. S3, data set S1 and Supplement S2). RWhighF was used as a reference for the optimization of the MAIDEN parameters, while the observed and simulated low frequencies were compared after the optimization of the model parameters. MAIDEN outputs were simulated for the central point of the source area of ring width data over the 1950-2010 period.

\subsubsection{Climate data}

MAIDEN needs daily climate data as inputs. These data were obtained from the gridded interpolated Canadian database of daily minimum-maximum temperature and precipitation for 1950-2015 (Hutchinson et al., 2009; http://cfs.nrcan.gc.ca/ projects/3/4). $\mathrm{CO}_{2}$ atmospheric concentration values for the same period were obtained by extrapolating data from the CarbonTracker measurement and modeling system (20002015 period; Peters et al., 2007; http://www.esrl.noaa.gov/ gmd/ccgg/carbontracker/) and the Mauna Loa Observatory (1958-2015; Keeling et al., 1976; http://www.esrl.noaa.gov/ $\mathrm{gmd} / \mathrm{ccgg} /$ trends/). Additional information can be found in Supplement S2.

\subsection{Response function analysis}

Linear response functions are regression models used to quantify the proportion of the variability of the observed data (stem growth or GPP in our case) that can be explained by climate variables. These functions do not directly explore mechanistic rules such as process-based models and are only optimized to achieve the best fit. Thus, comparing the results of linear functions and process-based models can help verify if model performance is satisfactory and if an important climatic factor related to a specific process is missing in the 

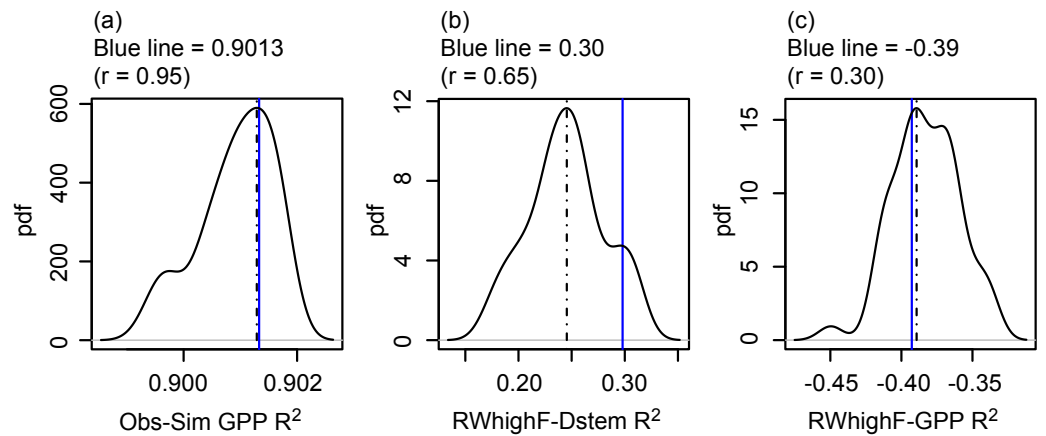

Figure 2. Variance explained by the model. (a) $R^{2}$ between observed and simulated GPP daily values. $R^{2}$ (computed on data transformed to $z$ scores) between the mean of the detrended series of black spruce ring growth (RWhighF) and simulated yearly detrended $\mathrm{C}$ allocation to the stem (b) or GPP (c). Vertical dashed line is the mode, and the blue line is the value with plausible block GPP (in a) or with plausible block stem (in b, c). All probability density functions are based on 50 simulations.

model. We used linear response functions to analyze the relationships between observed daily GPP at EOBS and the daily mean, maximum and minimum temperatures or weekly precipitation (explored time lag from 0 to 30 days before; in the case of precipitation, lag $n$ indicated the sum of the daily precipitation of the week ending in day $n$ ). In this analysis, we excluded the winter days (days of the year between 15 November and 1 April) where GPP is zero. The 10 predictors most strongly correlated with GPP (and not highly correlated with each other; pairwise $r \in[-0.8,0.8])$ were retained for the analysis. All linear response functions, resulting from a combination of these 10 predictors, were tested and classed according to their Bayesian information criterion (BIC).

We also used linear response functions to analyze the relationships between RWhighF and climate variables (same methodology as for GPP). We tested all monthly temperature and precipitation values of the previous and current years as predictors. Time windows of 31 days were used to obtain the time series of monthly data (over the 1950-2010 period) for each day (central day), averaging the values of each window and each year. These climate time series were also detrended.

\section{Results}

\subsection{GPP and tree-ring growth variability explained by MAIDEN}

The optimized model (see parameters' posterior distributions in Figs. S4 and S5) explained a large proportion of the observed GPP daily variability $(90 \% ; r=0.95, \mathrm{df}=2918$, $p<0.001$; Fig. 2a). Although the model was optimized with daily data, the GPP time series also reproduced the annual variability of the observed data quite well (Fig. 3).

As expected, the ring growth variability at our sites was more linked to temperature than to precipitation variables (see Fig. 4a and Gennaretti et al., 2014; Mamet and Kershaw, 2011; Nicault et al., 2014). The model reproduced this correlation pattern (Fig. 4b) and explained approximately $20-30 \%$ of the observed yearly RWhighF variability, corresponding to correlations of $0.58-0.66(\mathrm{df}=59, p<0.001$; Figs. 2b and S6). This result is good because the simulated detrended annual GPP values (i.e., photosynthetic assimilation before any carbon allocation) had only a negative $R^{2}$ with RWhighF (Fig. 2c; meaning performance was worse than a straight line centered on RWhighF) and much lower correlations (Figs. S6 and S7). The variance explained by the model increased when the time series of stem growth were analyzed with their trends $\left(R^{2}=0.73\right.$ and $r=0.86, \mathrm{df}=59$, $p<0.001$; Fig. $5 b)$. The positive trend in response to the warming of the last few decades was well captured by the model simulations of stem increments, which included some $\mathrm{CO}_{2}$ fertilization contribution (Fig. S8).

\subsection{Mechanistic and regression-based diagnostics}

The modeled impact of temperature on the maximum rate of Rubisco-catalyzed carboxylation ( $\mathrm{Vcmax}$ ) is shown in Fig. S9. This figure was obtained using Eqs. (1) and (3) with the parameters of plausible block GPP and using actual temperature data. The obtained $\mathrm{Vcmax}$ values (up to $30 \mu \mathrm{mol} \mathrm{C} \mathrm{m}{ }^{-2}$ of leaves $\mathrm{s}^{-1}$; Fig. S9c) were comparable to those obtained for another mature black spruce forest in Saskatchewan, Canada (Rayment et al., 2002). Furthermore, the impact of soil water content on the water stress level $(\theta g)$ influencing the stomatal conductance is shown in Fig. S10. Simulated GPP values were sensitive to all single parameters controlling Vcmax or $\theta g$, except soilb (Fig. S11$\mathrm{S} 15)$. The temperature transformation $(S)$ introduced here in MAIDEN also influenced the simulation results (Fig. 6). With no time delay between photosynthesis and temperature increases (i.e., $\tau=1$ and $S=$ Tday), MAIDEN overreacted to temperature variations in spring, and the GPP annual cycle was antedated (the start in spring and highest summer values were too early). In contrast, the use of $S$ with $\tau$ values between 10 and 15 days synchronized the 
(a) Daily GPP values
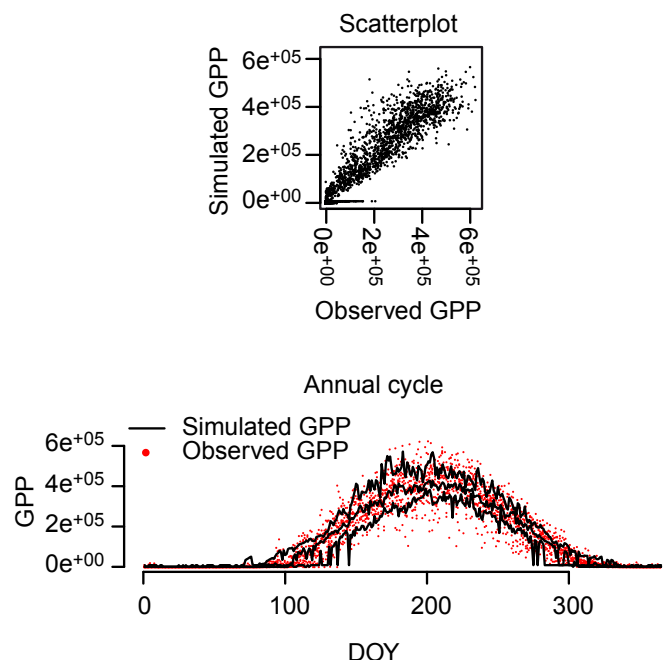

(b) Annual GPP values
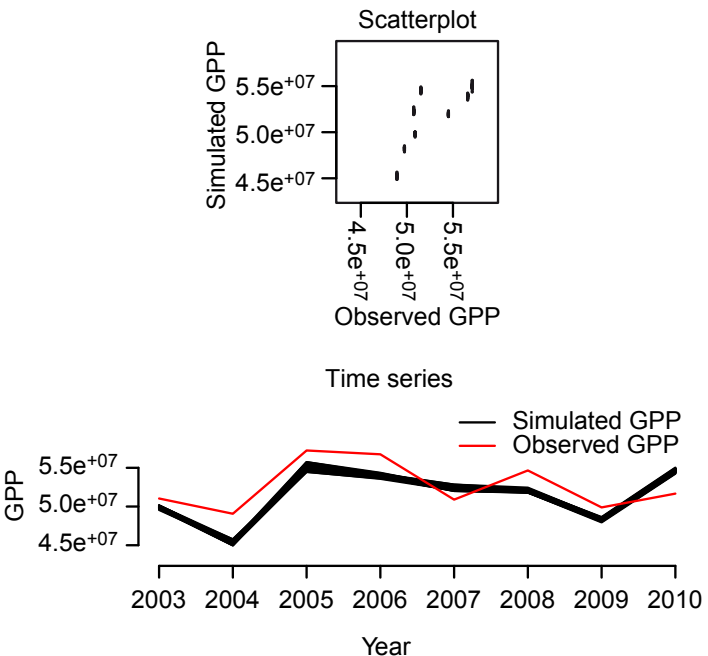

Figure 3. Comparison between observed GPP values and MAIDEN-simulated values at the Quebec Eastern Old Black Spruce site. (a) Daily values (units are $\left.\mu \mathrm{mol} \mathrm{C} \mathrm{m}{ }^{-2} \mathrm{day}^{-1}\right)$. In the scatterplot $\left(R^{2}=0.90 ; r=0.95, \mathrm{df}=2918, p<0.001\right.$ ), observations are compared with the values obtained with plausible block GPP. In the annual cycle plot, black lines are the medians and the 5th and the 95th percentiles of the simulated values from all iterations retained by the MCMC sampling. (b) Annual values (units are $\mu \mathrm{mol} \mathrm{C} \mathrm{m}^{-2} \mathrm{yr}^{-1}$ ). In both plots, observations are compared with the values from all iterations retained by the MCMC sampling. In the scatterplot, the $R^{2}$ of the data is 0.31 $(r=0.76, \mathrm{df}=6, p<0.05)$.

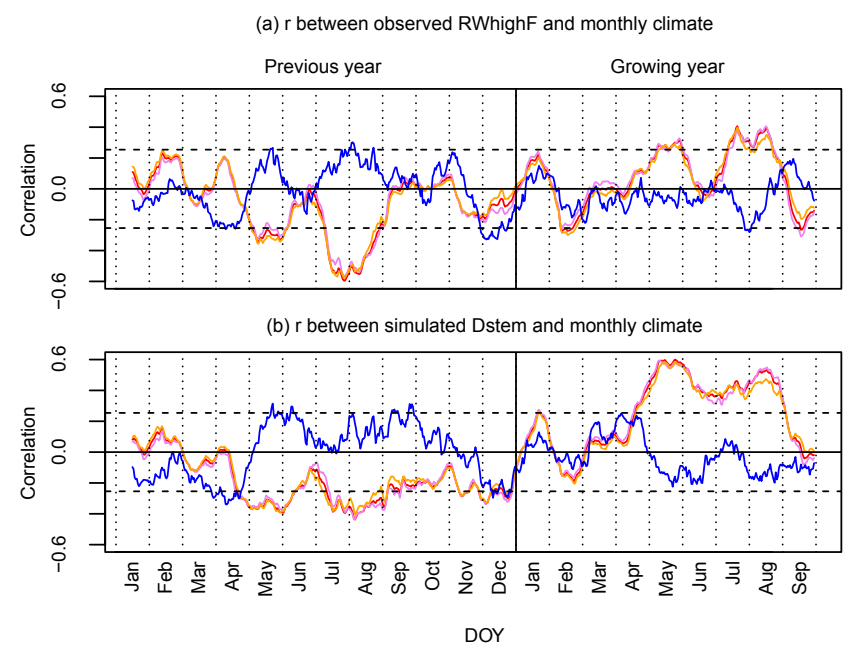

Figure 4. Correlation between monthly climate variables of the study area (precipitation in blue and mean, maximum and minimum temperature in red, violet and orange, respectively) and the mean of the detrended series of black spruce ring growth (RWhighF; a) and the simulated detrended annual carbon allocation to the stem (Dstem; b). For the climate variables, time windows of 31 days are used to obtain time series of monthly data (over the 1950 2010 period) for each day (central day), averaging the values of each window and each year. These climate time series are then detrended. Thresholds of significance $(p<0.05)$ are shown by horizontal dashed lines.
GPP annual cycle with observations. This result means that black spruce photosynthetic capacity needs approximately 10-15 days to acclimate to a higher daily temperature (e.g., $\tau$ equal to 12.43 days was selected for plausible block GPP). This time delay is a little longer than that previously found for black spruce but comparable to values found for Scots pine (Mäkelä et al., 2004; Gea-Izquierdo et al., 2010, 2014).

We modified important processes for carbon allocation to adapt MAIDEN to black spruce. For example, previous-year precipitation and temperature values influenced the potential maximum amount of carbon that the canopy could contain during the growing season, as illustrated in Fig. 7a (see Eq. 4). If both previous April precipitation and July-August temperature indexes are negative, then the potential amount of carbon simulated by the model would be maximum, otherwise it would be minimum. This result was consistent with the correlations shown in Fig. 4.

Another important process is the start of the growing season. According to our simulations, the start could not occur later than 17 June (Figs. S5d and S16; Table 1) and was influenced by the GDD sum and the photoperiod, which are known to be relevant for black spruce budburst along with the tree provenance (Rossi and Bousquet, 2014). However, because we added a mechanism to smooth yearly variations (see the day23_flex parameter), more years were needed by the plants to acclimate to variable GDD accumulations in winter-spring. With the selected parameters to simulate stem growth, the median onset of the growing season was 10 June (similar to observations for black spruce in northern Mani- 
(a) Detrended series

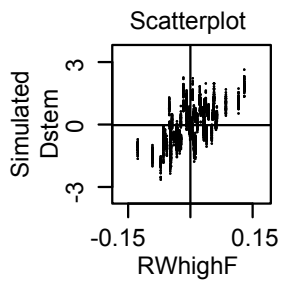

Time series

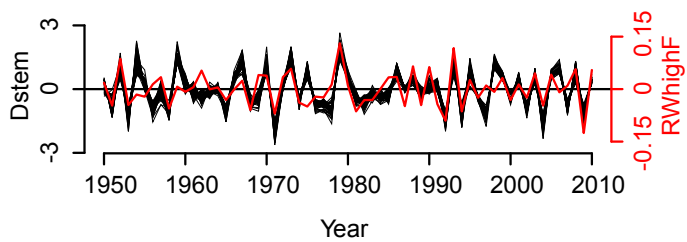

(b) Series with their trends

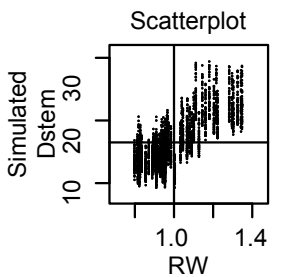

Time series

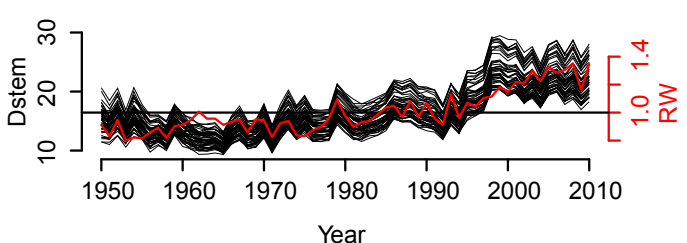

Figure 5. Comparison between the observed mean series of black spruce ring growth (unitless growth indexes) and MAIDEN-simulated carbon allocation to the stem (Dstem; $\mathrm{g} \mathrm{C} \mathrm{m}^{-2} \mathrm{yr}^{-1}$ ). (a) Detrended series (in the scatterplot the $R^{2}$ computed on data transformed to $z$ scores is $0.24 ; r=0.62, \mathrm{df}=59, p<0.001$ ). (b) Series with their trends (in the scatterplot the $R^{2}$ is $0.73 ; r=0.86, \mathrm{df}=59, p<0.001$ ). In all plots, observations are compared with the values from all iterations retained by the MCMC sampling.

toba, Canada; Bronson et al., 2009), with a standard deviation of 7.8 days. If the smoothing term was excluded, then the standard deviation increased to 9.4 days (see Fig. S16a). The inclusion of the smoothed mechanism also decreased the correlation between the simulated detrended annual Dstem and May average temperature from 0.70 to $0.59(\mathrm{df}=58$, $p<0.001)$. Although this correlation is still high, it was closer to the correlation between RWhighF and May temperature ( $r=0.27, \mathrm{df}=58, p<0.05$; Fig. 4$)$. These results show how the new model configuration decreased the yearly variability of the growth onset and helped achieve more plausible correlations with climate variables. According to the simulations, the onset of the growing season shifted by 7 days from 14 June to 7 June between the 1950-1970 and 19902010 periods (Fig. S16b-c). This result is consistent with the study of Bronson et al. (2009) on the effect of warming on black spruce budburst.

During phase 3, which corresponds to budburst, a portion of the available carbon simulated by MAIDEN comes from stored non-structural carbohydrates that are from the current and previous years (parameter Cbud; see Table 1). In our case, Cbud was quantified as approximately $1.69 \mathrm{~g} \mathrm{C} \mathrm{m}^{-2}$ day $^{-1}$ (Fig. S5f), and this remobilization improves the correlations between Dstem and RWhighF (Fig. S17). During phase 3 of our simulations, almost all available carbon was allocated to the canopy and roots $\left(h_{3} \approx 0.9905\right.$; Eq. 5; Fig. S5g; Table 1). For this reason, the previously used soil moisture and temperature dependences, determining the portion of carbon allocated to the stem in Mediterranean evergreen woodlands (Gea-Izquierdo et al., 2015), did not improve the results and could be excluded here. The partition of carbon during the growth and accumulation phase in summer (phase 4) was instead modeled as a function of temperature (Eq. 6). The simulations were highly sensitive to the st4temp parameter (Fig. 8c-d), and warmer temperatures corresponded to a greater amount of carbon allocated to the stem and less to non-structural carbohydrates (Fig. 8a-b). These results are in line with those of Cuny et al. (2015), who showed that woody biomass production is low in the first part of the growing season for most coniferous tree species because production follows the seasonal course of temperature (highest peak in summer). The simulated accumulation of carbon to the stem ended each year when the photoperiod became shorter than approximately $13.41 \mathrm{~h}$ (Fig. S5i; Table 1), corresponding to 2 September. The model performance was very sensitive to this parameter, which is known to impact black spruce dormancy induction (D'aoust and Cameron, 1982).

Another important process for carbon allocation is the loss of carbon from the canopy, a process that influences the seasonal course of the photosynthetic capacity. According to the simulations, the canopy mean annual turnover rate was approximately 13-14\% (Fig. S5j; Table 1), which corresponds well to previously published values for boreal spruce species (Ťupek et al., 2015). The simulated annual cycle of canopy losses (Fig. S18) culminated on 2 July, and $80 \%$ of litterfall occurred between 27 May and 19 July. This cycle is also similar to published results showing that the majority of litterfall $(\approx 80 \%)$ occurs in summer during needle growth for conifer species (Maseyk et al., 2008).

The comparison between MAIDEN simulations and classic linear response functions confirmed the quality and 

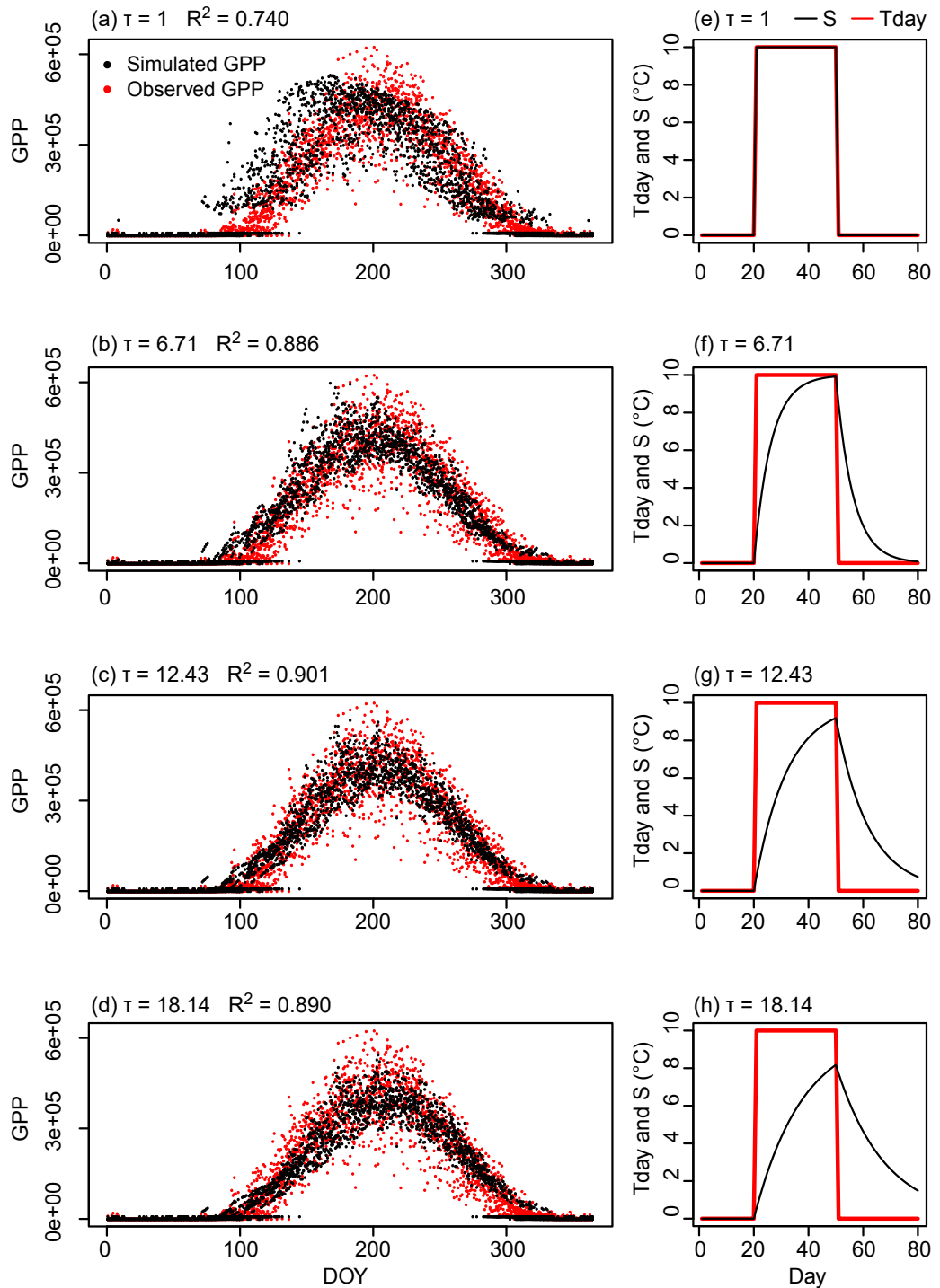

Figure 6. Influence of the temperature transformation $(S)$ on the modeled annual cycle of GPP daily values $\left(\mu \mathrm{mol} \mathrm{C \textrm {m } ^ { - 2 } \text { day }}{ }^{-1}\right)$ at the Quebec Eastern Old Black Spruce site. Only the $\tau$ parameter determining the $S$ values was allowed to vary, while the other parameters were fixed to the values of plausible block GPP. (a) $\tau$ is 1 day ( $S$ same as Tday). (b) $\tau$ is 6.71 days (a middle value between 1 and 12.43 ). (c) $\tau$ is 12.43 days (same $\tau$ than in plausible block GPP). (d) $\tau$ is 18.14 days (a higher value than in plausible block GPP). The $R^{2}$ between observations and simulations is reported in each plot. Panels (e-h) show the impact of the respective $\tau$ values on $S$ if the daily Tday time series corresponds to a single step of $10^{\circ} \mathrm{C}$ lasting 30 days.

plausibility of the simulated results with the process-based model. MAIDEN performed better than response functions in explaining the variability of the daily GPP $\left(R^{2}=0.90\right.$ vs. 0.69; Table 2). In the case of annual radial growth, the explained variability with the best response function (50\%; Table 3) was greater than with MAIDEN (20$30 \% ; r \approx 0.65, \mathrm{df}=59, p<0.001$; Fig. $2 b$ ). However, the MAIDEN-simulated time series maintained the relationship with the significant monthly climate variables detected in the response function analysis. Correlation coefficients of $-0.39,0.46$ and $0.57(\mathrm{df}=58, p<0.01)$ were obtained between MAIDEN Dstem $\left(\mathrm{g} \mathrm{C} \mathrm{m}^{-2} \mathrm{yr}^{-1}\right)$ and previous July-
August, growing-year July and growing-year May-June temperature values, respectively (Fig. $4 \mathrm{~b}$; these coefficients are for comparison with those in Table 3).

\section{Discussion}

In this study, the MAIDEN model was successfully modified to consider important processes for boreal tree species and to improve the simulation of the coupling between photosynthesis and carbon allocation to the stem in boreal forests. Because we used a Bayesian optimization procedure, we start 
(b) RW - Dstem

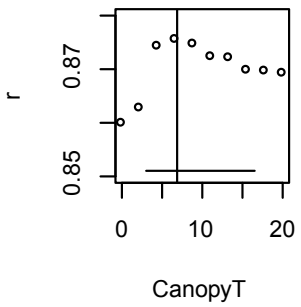

(c) RWhighF - detrended Dstem

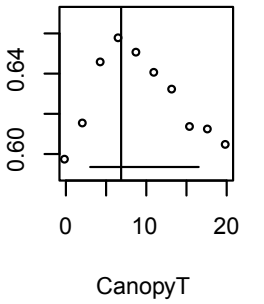

(d) RW - Dstem

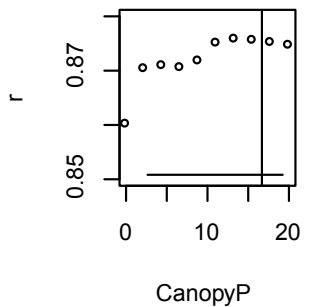

(e) RWhighF - detrended Dstem

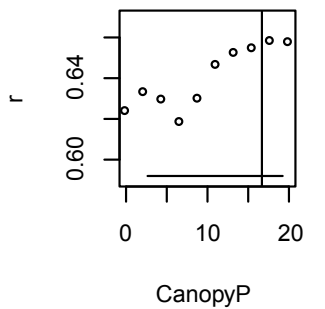

Figure 7. Temperature and precipitation dependence of CanopyMult (a; unitless multiplier; Eq. 4; CanopyT and CanopyP are those of plausible block stem), which determines the yearly canopy potential amount of carbon. Previous-year mean July-August temperature indexes are on the $x$ axis, and previous-year April precipitation indexes are on the $y$ axis. Black dots are observed values in the central point of the region with ring width data. Panels (b-e) show how CanopyT and CanopyP (varying over their prior acceptable ranges) impact the correlations between simulated Dstem $\left(\mathrm{g} \mathrm{C} \mathrm{m}^{-2} \mathrm{yr}^{-1}\right.$ ) and observed ring width data (RW or RWhighF; unitless indexes), when all other parameters are fixed to the values of plausible block stem. The vertical lines are the selected values for plausible block stem, and the horizontal lines are the $90 \%$ confidence intervals based on the parameters' posterior densities (Fig. S5).

the following discussion with the interpretation of the parameters' posterior distributions (Sect. 4.1) and of the simulation uncertainties (Sect. 4.2). Subsequently, some model predictions at the 2050 horizon are presented to identify the likely response of the studied boreal forests under future environmental change (Sect. 4.3). Finally, we conclude by illustrating factors that may potentially influence the obtained results (Sect. 4.4).

\subsection{Parameter interpretation}

The posterior distributions of the parameters were relatively sharp (Figs. S4 and S5; Table 1; by sharpness, we mean the shrinking of the distribution relative to the prior acceptable range toward a posterior distribution with a well-defined, narrow peak). Sharp distributions with small posterior ranges relative to the prior ones indicate sensitive parameters. This result means that the model posterior probability (i.e., model plausibility) increased significantly with the specific values of the selected parameters retained by the MCMC sampling. The slightly bimodal structures of the posterior distributions of $\mathrm{Vmax}, \mathrm{Vb}$ and Vip were likely a consequence of their significant cross-correlations (Table S1). However, the posterior distributions of these three parameters were robust and consistent even when the Bayesian optimization was executed on independent periods (Fig. S19). The optimization of some parameters controlling Dstem (the three related to the start of the growing season and Cbud) was sensitive to the choice of the period and the site in the cross-validation exercise (Figs. S20 and S21), likely as a result of the short length of the available observed data (61 yearly RWhighF values) and of significant cross-correlation coefficients (Table S2). However, in all cases, the uncertainties in the parameters' posterior distributions (Figs. S4 and S5) did not affect our interpretations because the MAIDEN simulations were extremely consistent irrespective of the selected block of parameters (see Figs. 3 and 5).

The interpretation of some parameters needs specific attention, such as the parameters controlling the negative impact of both previous-year April precipitation and JulyAugust temperature values on canopy development. Warm previous Aprils with infrequent late snowfalls may accelerate snowmelt and the start of the previous growing season, allowing optimal reserve accumulation during the previous year, which then would influence tree performance the following growing year. This mechanism may be significant, especially if we do not observe high temperatures limiting soil water availability and reserve accumulation during the previous summer (Girardin et al., 2016). It has already been shown that shoot elongation of boreal conifers is determined by climate conditions during bud formation (Salminen and Jalkanen, 2005). However, for Scots pine, previous summer 
Table 2. ANOVA table for the best response function (here, a combination of 4 of the 10 tested predictors minimized the BIC) with daily GPP at EOBS as dependent variable (excluding days between 15 November and 1 April). All $F$ values are highly significant $(p<0.001)$. For precipitation, lag $n$ indicates the sum of the daily precipitation of the week ending in day $n$.

\begin{tabular}{|c|c|c|c|c|c|c|}
\hline \multirow[t]{2}{*}{ Predictor } & \multirow[t]{2}{*}{$\begin{array}{r}\text { Pairwise correlation } \\
\text { with GPP }\end{array}$} & \multicolumn{4}{|c|}{$\begin{array}{l}\text { ANOVA } \\
\text { table }\end{array}$} & \multirow[t]{2}{*}{$\mathrm{BIC}$} \\
\hline & & $\begin{array}{r}\text { Regression } \\
\text { coefficient }\end{array}$ & df & $\begin{array}{r}\text { Variance } \\
\text { explained }\end{array}$ & $F$ value & \\
\hline Maximum temperature - lag -2 days & 0.79 & 0.149 & 1 & 0.630 & 3716.16 & \\
\hline Maximum temperature - lag -19 days & 0.69 & 0.057 & 1 & 0.049 & 291.29 & \\
\hline Precipitation - lag -2 & 0.21 & 0.019 & 1 & 0.005 & 31.99 & \\
\hline Precipitation - lag -0 & 0.16 & -0.013 & 1 & 0.005 & 29.90 & \\
\hline Total variance explained & & & & 0.690 & & 5288.3 \\
\hline Residuals & & & 1827 & 0.310 & & \\
\hline Function with all 10 tested predictors & & & & 0.694 & & 5315.4 \\
\hline
\end{tabular}

Table 3. ANOVA table for the best response function (here, a combination of 3 of the 10 tested predictors minimized the BIC) with the observed mean detrended ring width series (RWhighF) as the dependent variable.

\begin{tabular}{|c|c|c|c|c|c|c|}
\hline \multirow[t]{2}{*}{$\begin{array}{l}\text { Predictor (monthly data around the } \\
\text { indicated day of the year) }\end{array}$} & \multirow[t]{2}{*}{$\begin{array}{r}\text { Pairwise correlation } \\
\text { with RWhighF }\end{array}$} & \multicolumn{4}{|c|}{$\begin{array}{l}\text { ANOVA } \\
\text { table }\end{array}$} & \multirow[t]{2}{*}{ BIC } \\
\hline & & $\begin{array}{c}\text { Regression } \\
\text { coefficient }\end{array}$ & $\mathrm{df}$ & $\begin{array}{r}\text { Variance } \\
\text { explained }\end{array}$ & $F$ value & \\
\hline Mean temperature - previous 28 July & -0.60 & -0.477 & 1 & 0.355 & $39.88^{* * *}$ & \\
\hline Mean temperature -22 July & 0.41 & 0.247 & 1 & 0.055 & $6.14^{*}$ & \\
\hline Maximum temperature - 30 May & 0.33 & 0.146 & 1 & 0.093 & $10.48^{* *}$ & \\
\hline Total variance explained & & & & 0.502 & & 148.7 \\
\hline Residuals & & & 56 & 0.498 & & \\
\hline Function with all 10 tested predictors & & & & 0.568 & & 169.0 \\
\hline
\end{tabular}

temperatures are positively correlated with shoot elongation, while in our case, the opposite process was simulated, and the simulations were even more sensitive to the values of the CanopyT temperature-dependent parameter than to those of the CanopyP precipitation-dependent parameter (Fig. 7b-e). We need more data on canopy development and shoot elongation to verify the model results.

\subsection{Interpretation of model performance}

The comparisons with the observed data suggest that MAIDEN as revised produces accurate simulations of GPP, of ring width and stem biomass variability and of intragrowing season dynamics. The explained variance $\left(R^{2}=\right.$ 0.73 and $r=0.86$, df $=59, p<0.001$; Fig. 5b) is higher than that explained by MAIDEN for Mediterranean sites $\left(R^{2}\right.$ slightly above 0.5 ; Gea-Izquierdo et al., 2015). However, the ensembles of daily and annual time series retained by the MCMC sampling were not always centered on the observed time series (Figs. 3 and 5). Specifically, the simulated annual GPP values often underestimated the actual GPP, especially at low observed GPP. This result reflects the fact that the MCMC sampling maximized the model plausibility according to the model structure and, by doing so, retained similar blocks of parameters. Thus, the range of simulated values in Figs. 3 and 5, obtained with all retained iterations, should be interpreted as the uncertainty due to only parameter selection, while the uncertainty due to the non-perfect fit between observations and simulations was not considered.

We drew the following conclusions based on the response function analysis. First, in the case of daily GPP (Table 2), MAIDEN performed better than response functions, suggesting that it properly simulates climate-driven processes governing photosynthetic assimilation, which are well known to be a result of several nonlinear processes. Second, most of the variance explained by the response functions was due to temperature variables, reflecting the greater sensitivity of northern black spruce forests to temperature compared to drought stress (Gennaretti et al., 2014) and justifying the modeling in MAIDEN of the maximum carboxylation rate as a function of temperature. Third, only temperature vari- 
(c) RW - Dstem
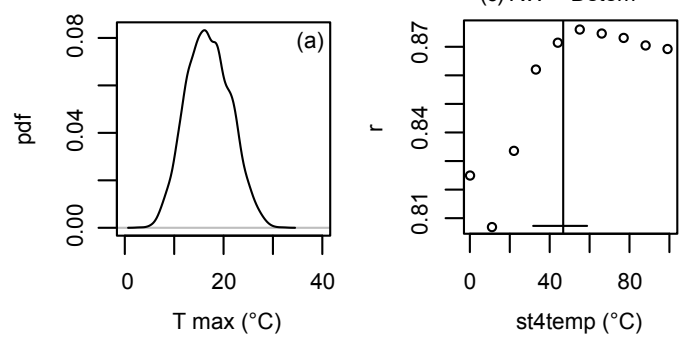

(d) RWhighF - detrended Dstem

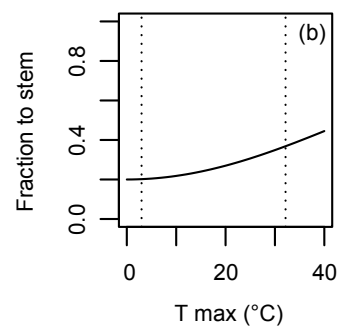

\subsection{Model predictions}

It is possible to use the new optimized MAIDEN to predict forest growth and allocation dynamics of the studied boreal forests under future environmental change. At the 2050 horizon, daily maximum temperature, daily minimum temperature and precipitation within the study area should increase by approximately $2.3{ }^{\circ} \mathrm{C}, 4.3^{\circ} \mathrm{C}$ and $12 \%$, respectively (Guay et al., 2015). If we modify the climate data used (Sect. 2.2.3) with these median changes and we fix the $\mathrm{CO}_{2}$ concentration at the 2010 level, then the median increase in the annual GPP and Dstem values simulated by MAIDEN for the studied forests is 43 and $68 \%$, respectively (Fig. S22). It is important to note that the ring width data used for the optimization of MAIDEN come from lake riparian trees and that these results are too optimistic for more water-limited boreal sites.

\subsection{Limits and error sources of the study}

bon in phase 4 (growth and accumulation phase in summer) when MAIDEN is run with the parameters of plausible block stem at the center of the region with ring width data in the northern Quebec taiga. (a) Probability density of daily maximum temperature values in summer. (b) Relationship between maximum temperature values and portion of carbon allocated to the stem (Eq. 6). The vertical dashed lines show the range of maximum temperature values. Panels (c-d) show how the parameter st 4 temp influencing this process impacts the correlations between simulated Dstem and observed ring width data (RW or RWhighF) when all other parameters are fixed to the values of plausible block stem and st4temp varies over its prior acceptable range. The vertical line is the selected value for plausible block stem, and the horizontal line is the $90 \%$ confidence interval based on the parameter's posterior density (Fig. S5).

ables of preceding days were retained, justifying the inclusion of our acclimation function of photosynthesis into temperature to increase the influence of previous days. Fourth, the coefficient estimate for precipitation of lag 0 (i.e., week ending in day 0 ) was negative, while that of lag -2 was positive, even though these variables share 5 of 7 days of data. The reduction of absorbed photosynthetically active radiation associated with cloudiness during raining days could explain this result. In the case of annual stem growth (Table 3), the explained variability with the best response function was greater than with MAIDEN, suggesting that the process-based modeling can potentially be improved with additional data and by including stronger legacy effects of the year preceding ring formation (Girardin et al., 2016). Indeed, most of the variance explained by the response function was due to a negative correlation with the temperature of the previous summer. Contrasting correlations with summer temperature values of the previous and the current growing year are also visible in Fig. 4a and have already been observed for black spruce (Mamet and Kershaw, 2011; Ols et al., 2016).
Although the simulated results with MAIDEN were satisfactory, we have to consider two important limits and error sources of the study. First, for the optimization of carbon allocation, we assumed that stem biomass (or carbon) increments were proportional to ring growth. This approach was necessary because data from field plots were not available from all study sites. A recent study showed that the maximum rate of ring width increase during the growing season precedes the maximum rate of increase in wood biomass and that these processes could exhibit differential sensitivities to local environmental conditions (Cuny et al., 2015). However, Cuny et al. (2015) also highlighted that wood biomass production follows the seasonal course of temperature in coniferous forests, and this is what we observed once MAIDEN was optimized. Indeed, almost all available carbon in spring was allocated to the canopy and roots (Fig. S5g; Table 1), whereas $\mathrm{C}$ allocation to the stem (Dstem) in summer increased with temperature (Fig. 8). Furthermore, the ring width series used were highly correlated with July-August temperature, as expected for wood biomass production and for climate-growth analysis for the studied species. Second, some fixed parameters are present in the MAIDEN code (see Eqs. 4 and 6). These parameters may be potentially modified, but their specification is justified in Sect. 2.1.2 and limits additional parameter tuning. Third, we modeled GPP and carbon stem increments of a boreal tree species using mechanistic rules, which increased the capability of MAIDEN to reproduce observed variations. However, our choice of mechanistic rules was subjective to some extent and depended on previous physiological knowledge and on model-data comparisons. Such model refining is an important step of all model-data fusion approaches (Guiot et al., 2014) and increases our understanding of ecosystem functioning and responses. Nevertheless, the proposed mechanistic rules should 
be verified in the future with additional data from a wider boreal area.

\section{Conclusion}

In this study, we adapted a process-based forest ecophysiological model developed for temperate and Mediterranean forests to simulate gross primary production and stem biomass increment for black spruce, the dominant species across the North American boreal biome. The model used, MAIDEN (Misson, 2004; Gea-Izquierdo et al., 2015), has the specificity to simultaneously simulate the course of photosynthesis and phenological phases characterized by specific allocation rules dependent on climatic conditions. The model represented the tree-ring interannual variability even though detrended radial growth was poorly explained by the simulated annual GPP (Fig. 2b-c), which suggests that the relationship between GPP and wood production is complex and nonlinear (Rocha et al., 2006). Significant simulation improvements were obtained, introducing important processes for temperature-sensitive boreal forests into the model, such as (i) the acclimation of photosynthesis to temperature over several days (see Gea-Izquierdo et al., 2010; Mäkelä et al., 2004), (ii) the influence of previous-year climatic conditions affecting bud formation on the potential amount of carbon allocated to the canopy each year (see Salminen and Jalkanen, 2005) and (iii) the positive relationship between temperature and the carbon allocated to the stem in summer (see Cuny et al., 2015). Although we used black spruce data from the northern Quebec taiga to test and optimize the model, the new model modifications have the potential to work within other boreal regions and tree species. The effects of the introduced functions can be amplified, reduced or canceled in the Bayesian optimization procedure according to the relevance of specific processes in the studied forest.

Boreal ecosystems are crucial carbon stores that must be quantified and preserved (Bradshaw et al., 2009). Their future evolution is extremely important for the global carbon budget. Development of process-based models, such as the one used and improved here, combined with continuous field data acquisition will help determine the role of the different environmental factors and underlying mechanisms in present and future boreal forest carbon fluxes. In this context, we believe that our study helps to explain how boreal forests assimilate and allocate carbon depending on weather/climate conditions.

Data availability. The MAIDEN version used is publicly available on "Figshare": https://doi.org/10.6084/m9.figshare.5446435 (Gennaretti, 2017).

The Supplement related to this article is available online at https://doi.org/10.5194/bg-14-4851-2017-supplement.
Competing interests. The authors declare that they have no conflict of interest.

Acknowledgements. This project has received funding from the European Union's Horizon 2020 research and innovation programme under the Marie Sklodowska-Curie grant agreement no. 656896 and from the ECCOREV research federation. The CRD NSERC ARCHIVES project funded the sampling of the tree-ring data. We acknowledge all institutes and persons providing the other data used: Natural Resources Canada for the climate data; NOAA Earth System Research Laboratory for the $\mathrm{CO}_{2}$ data; the Fluxnet project and Hank Margolis (Université Laval) for the eddy covariance data; Gabriel Rodrigue for the soil data at our tree-ring sites.

Edited by: Anja Rammig

Reviewed by: two anonymous referees

\section{References}

Bergeron, O., Margolis, H. A., Black, T. A., Coursolle, C., Dunn, A. L., Barr, A. G., and Wofsy, S. C.: Comparison of carbon dioxide fluxes over three boreal black spruce forests in Canada, Glob. Change Biol., 13, 89-107, https://doi.org/10.1111/j.13652486.2006.01281.x, 2007.

Berninger, F., Hari, P., Nikinmaa, E., Lindholm, M., and Meriläinen, J.: Use of modeled photosynthesis and decomposition to describe tree growth at the northern tree line, Tree Physiol., 24, 193-204, https://doi.org/10.1093/treephys/24.2.193, 2004.

Bond-Lamberty, B., Wang, C., and Gower, S. T.: Aboveground and belowground biomass and sapwood area allometric equations for six boreal tree species of northern Manitoba, Can. J. Forest Res., 32, 1441-1450, https://doi.org/10.1139/x02-063, 2002a.

Bond-Lamberty, B., Wang, C., Gower, S. T., and Norman, J.: Leaf area dynamics of a boreal black spruce fire chronosequence, Tree Physiol., 22, 993-1001, https://doi.org/10.1093/treephys/22.14.993, 2002b.

Boucher, É., Guiot, J., Hatté, C., Daux, V., Danis, P.-A., and Dussouillez, P.: An inverse modeling approach for tree-ring-based climate reconstructions under changing atmospheric $\mathrm{CO}_{2}$ concentrations, Biogeosciences, 11, 3245-3258, https://doi.org/10.5194/bg-11-3245-2014, 2014.

Bradshaw, C. J. A., Warkentin, I. G., and Sodhi, N. S.: Urgent preservation of boreal carbon stocks and biodiversity, Trends Ecol. Evol., 24, 541-548, https://doi.org/10.1016/j.tree.2009.03.019, 2009.

Bronson, D. R., Gower, S. T., Tanner, M., and Van Herk, I.: Effect of ecosystem warming on boreal black spruce bud burst and shoot growth, Glob. Change Biol., 15, 1534-1543, https://doi.org/10.1111/j.1365-2486.2009.01845.x, 2009.

Chen, J. M.: Optically-based methods for measuring seasonal variation of leaf area index in boreal conifer stands, Agr. Forest Meteorol., 80, 135-163, https://doi.org/10.1016/01681923(95)02291-0, 1996.

Cuny, H. E., Rathgeber, C. B. K., Frank, D., Fonti, P., Makinen, H., Prislan, P., Rossi, S., Del Castillo, E. M., Campelo, F., Vavrci, H., Camarero, J. J., Bryukhanova, M. V., Jyske, T., Gricar, J., Gryc, 
V., De Luis, M., Vieira, J., Cufar, K., Kirdyanov, A. V., Oberhuber, W., Treml, V., Huang, J. G., Li, X., Swidrak, I., Deslauriers, A., Liang, E., Nojd, P., Gruber, A., Nabais, C., Morin, H., Krause, C., King, G., and Fournier, M.: Woody biomass production lags stem-girth increase by over one month in coniferous forests, Nature Plants, 1, 1-6, https://doi.org/10.1038/nplants.2015.160, 2015.

Czapowskyj, M. M., Robinson, D. J., Briggs, R. D., and White, E. H.: Component biomass equations for black spruce in Maine, USDA, Forest Service, Northeastern Forest Experiment Station, Research report NE-564, 1985.

Danis, P. A., Hatté, C., Misson, L., and Guiot, J.: MAIDENiso: a multiproxy biophysical model of tree-ring width and oxygen and carbon isotopes, Can. J. Forest Res., 42, 1697-1713, https://doi.org/10.1139/x2012-089, 2012.

D'aoust, A. L. and Cameron, S. I.: The effect of dormancy induction, low temperatures and moisture stress on cold hardening of containerized black spruce seedlings, in: Proceedings of the Canadian Containerized Tree Seedling Symposium, Toronto, Ontario, 14-16 September 1981, 153-161, 1982.

De Pury, D. G. G. and Farquhar, G. D.: Simple scaling of photosynthesis from leaves to canopies without the errors of big-leaf models, Plant Cell Environ., 20, 537-557, https://doi.org/10.1111/j.1365-3040.1997.00094.x, 1997.

Fatichi, S., Leuzinger, S., and Körner, C.: Moving beyond photosynthesis: from carbon source to sink-driven vegetation modeling, New Phytol., 201, 1086-1095, https://doi.org/10.1111/nph.12614, 2014.

Gaucherel, C., Campillo, F., Misson, L., Guiot, J., and Boreux, J. J.: Parameterization of a process-based tree-growth model: Comparison of optimization, MCMC and Particle Filtering algorithms, Environ. Modell. Softw., 23, 1280-1288, https://doi.org/10.1016/j.envsoft.2008.03.003, 2008a.

Gaucherel, C., Guiot, J., and Misson, L.: Changes of the potential distribution area of French Mediterranean forests under global warming, Biogeosciences, 5, 1493-1504, https://doi.org/10.5194/bg-5-1493-2008, 2008b.

Gea-Izquierdo, G., Mäkelä, A., Margolis, H., Bergeron, Y., Black, T. A., Dunn, A., Hadley, J., Paw U, K. T., Falk, M., Wharton, S., Monson, R., Hollinger, D. Y., Laurila, T., Aurela, M., McCaughey, H., Bourque, C., Vesala, T., and Berninger, F.: Modeling acclimation of photosynthesis to temperature in evergreen conifer forests, New Phytol., 188, 175-186, https://doi.org/10.1111/j.1469-8137.2010.03367.x, 2010.

Gea-Izquierdo, G., Bergeron, Y., Huang, J. G., Lapointe-Garant, M. P., Grace, J., and Berninger, F.: The relationship between productivity and tree-ring growth in boreal coniferous forests, Boreal Environ. Res., 19, 363-378, 2014.

Gea-Izquierdo, G., Guibal, F., Joffre, R., Ourcival, J. M., Simioni, G., and Guiot, J.: Modelling the climatic drivers determining photosynthesis and carbon allocation in evergreen Mediterranean forests using multiproxy long time series, Biogeosciences, 12, 3695-3712, https://doi.org/10.5194/bg-12-3695-2015, 2015.

Gea-Izquierdo, G., Nicault, A., Battipaglia, G., Dorado-Liñán, I., Gutiérrez, E., Ribas, M., and Guiot, J.: Risky future for Mediterranean forests unless they undergo extreme carbon fertilization, Glob. Change Biol., 23, 2915-2927, https://doi.org/10.1111/gcb.13597, 2017.
Gennaretti, F.: MAIDEN ecophysiological forest model, https://doi.org/10.6084/m9.figshare.5446435, 2017.

Gennaretti, F., Arseneault, D., Nicault, A., Perreault, L., and Bégin, Y.: Volcano-induced regime shifts in millennial tree-ring chronologies from northeastern North America, P. Natl. Acad. Sci. USA, 111, 10077-10082, https://doi.org/10.1073/pnas.1324220111, 2014.

Girardin, M. P., Raulier, F., Bernier, P. Y., and Tardif, J. C.: Response of tree growth to a changing climate in boreal central Canada: A comparison of empirical, process-based, and hybrid modelling approaches, Ecol. Model., 213, 209-228, https://doi.org/10.1016/j.ecolmodel.2007.12.010, 2008.

Girardin, M. P., Hogg, E. H., Bernier, P. Y., Kurz, W. A., Guo, X. J., and Cyr, G.: Negative impacts of high temperatures on growth of black spruce forests intensify with the anticipated climate warming, Glob. Change Biol., 22, 627-643 https://doi.org/10.1111/gcb.13072, 2016.

Guay, C., Minville, M., and Braun, M.: A global portrait of hydrological changes at the 2050 horizon for the province of Québec, Can. Water Resour. J., 40, 285-302, https://doi.org/10.1080/07011784.2015.1043583, 2015.

Guiot, J., Boucher, E., and Gea Izquierdo, G.: Process models and model-data fusion in dendroecology, Frontiers in Ecology and Evolution, 2, 52, https://doi.org/10.3389/fevo.2014.00052, 2014.

Hutchinson, M. F., McKenney, D. W., Lawrence, K., Pedlar, J. H., Hopkinson, R. F., Milewska, E., and Papadopol, P.: Development and testing of Canada-wide interpolated spatial models of daily minimum-maximum temperature and precipitation for 1961-2003, J. Appl. Meteorol. Clim., 48, 725-741, https://doi.org/10.1175/2008jamc1979.1, 2009.

Jenkins, J. C., Chojnacky, D. C., Heath, L. S., and Birdsey, R. A.: National-Scale Biomass Estimators for United States Tree Species, Forest Sci., 49, 12-35, 2003.

Keeling, C. D., Bacastow, R. B., Bainbridge, A. E., Ekdahl, C. A., Guenther, P. R., Waterman, L. S., and Chin, J. F. S.: Atmospheric carbon dioxide variations at Mauna Loa Observatory, Hawaii, Tellus, 28, 538-551, https://doi.org/10.1111/j.21533490.1976.tb00701.x, 1976.

Kirdyanov, A., Hughes, M., Vaganov, E., Schweingruber, F., and Silkin, P.: The importance of early summer temperature and date of snow melt for tree growth in the Siberian Subarctic, TreesStruct. Funct., 17, 61-69, https://doi.org/10.1007/s00468-0020209-z, 2003.

Lemieux, J.: Phénologie de l'épinette noire dans le haut boréal: un patron de la croissance intra-annuelle primaire et secondaire en relation avec la température de l'air journalière, Master of Biology, Université du Québec à Montréal, Montreal, 90 pp., 2010.

Leuning, R.: A critical appraisal of a combined stomatalphotosynthesis model for C3 plants, Plant Cell Environ., 18, 339-355, https://doi.org/10.1111/j.1365-3040.1995.tb00370.x, 1995.

Li, G., Harrison, S. P., Prentice, I. C., and Falster, D.: Simulation of tree-ring widths with a model for primary production, carbon allocation, and growth, Biogeosciences, 11, 6711-6724, https://doi.org/10.5194/bg-11-6711-2014, 2014.

Li, G., Harrison, S. P., and Prentice, I. C.: A model analysis of climate and $\mathrm{CO}_{2}$ controls on tree growth and carbon allocation in a semi-arid woodland, Ecol. Model., 342, 175-185, https://doi.org/10.1016/j.ecolmodel.2016.10.005, 2016. 
Mäkelä, A., Berninger, F., and Hari, P.: Optimal control of gas exchange during drought: Theoretical analysis, Ann. Bot.-London, 77, 461-467, https://doi.org/10.1006/anbo.1996.0056, 1996.

Mäkelä, A., Hari, P., Berninger, F., Hänninen, H., and Nikinmaa, E.: Acclimation of photosynthetic capacity in Scots pine to the annual cycle of temperature, Tree Physiol., 24, 369-376, https://doi.org/10.1093/treephys/24.4.369, 2004.

Mamet, S. D. and Kershaw, G. P.: Radial-Growth Response of Forest-Tundra Trees to Climate in the Western Hudson Bay Lowlands, Arctic, 64, 446-458, 2011.

Man, R. and Lu, P.: Effects of thermal model and base temperature on estimates of thermal time to bud break in white spruce seedlings, Can. J. Forest Res., 40, 1815-1820, https://doi.org/10.1139/X10-129, 2010.

Maseyk, K. S., Lin, T., Rotenberg, E., Grünzweig, J. M., Schwartz, A., and Yakir, D.: Physiology-phenology interactions in a productive semi-arid pine forest, New Phytol., 178, 603-616, https://doi.org/10.1111/j.1469-8137.2008.02391.x, 2008.

Misson, L.: MAIDEN: a model for analyzing ecosystem processes in dendroecology, Can. J. Forest Res., 34, 874-887, https://doi.org/10.1139/x03-252, 2004.

Misson, L., Rathgeber, C., and Guiot, J.: Dendroecological analysis of climatic effects on Quercus petraea and Pinus halepensis radial growth using the process-based MAIDEN model, Can. J. Forest Res., 34, 888-898, https://doi.org/10.1139/x03-253, 2004.

Moorcroft, P. R.: How close are we to a predictive science of the biosphere?, Trends Ecol. Evol., 21, 400-407, https://doi.org/10.1016/j.tree.2006.04.009, 2006.

Nicault, A., Boucher, E., Tapsoba, D., Arseneault, D., Berninger, F., Bégin, C., DesGranges, J. L., Guiot, J., Marion, J., Wicha, S., and Bégin, Y.: Spatial analysis of the black spruce (Picea mariana [MILL] B.S.P.) radial growth response to climate in northern Québec, Canada, Can. J. Forest Res., 45, 343-352, https://doi.org/10.1139/cjfr-2014-0080, 2014.

Nitschke, C. R. and Innes, J. L.: A tree and climate assessment tool for modelling ecosystem response to climate change, Ecol. Model., 210, 263-277, https://doi.org/10.1016/j.ecolmodel.2007.07.026, 2008.

Ols, C., Hofgaard, A., Bergeron, Y., and Drobyshev, I.: Previous season climate controls the occurrence of black spruce growth anomalies in boreal forests of Eastern Canada, Can. J. Forest Res., 46, 696-705, https://doi.org/10.1139/cjfr-2015-0404, 2016.

Peters, W., Jacobson, A. R., Sweeney, C., Andrews, A. E., Conway, T. J., Masarie, K., Miller, J. B., Bruhwiler, L. M. P., Pétron, G., Hirsch, A. I., Worthy, D. E. J., van der Werf, G. R., Randerson, J. T., Wennberg, P. O., Krol, M. C., and Tans, P. P.: An atmospheric perspective on North American carbon dioxide exchange: CarbonTracker, P. Natl. Acad. Sci. USA, 104, 1892518930, https://doi.org/10.1073/pnas.0708986104, 2007.
Rayment, M. B., Loustau, D., and Jarvis, P. J.: Photosynthesis and respiration of black spruce at three organizational scales: shoot, branch and canopy, Tree Physiol., 22, 219-229, https://doi.org/10.1093/treephys/22.4.219, 2002.

Robert, C.: Méthodes de Monte Carlo par chaînes de Markov, Statistique mathématique et Probabilité, edited by: Deheuvels, P., Economica, Paris, 1996.

Rocha, A. V., Goulden, M. L., Dunn, A. L., and Wofsy, S. C.: On linking interannual tree ring variability with observations of whole-forest $\mathrm{CO}_{2}$ flux, Glob. Change Biol., 12, 1378-1389, https://doi.org/10.1111/j.1365-2486.2006.01179.x, 2006.

Rossi, S. and Bousquet, J.: The bud break process and its variation among local populations of boreal black spruce, Front. Plant Sci., 5, 574, https://doi.org/10.3389/fpls.2014.00574, 2014.

Rossi, S., Anfodillo, T., Čufar, K., Cuny, H. E., Deslauriers, A., Fonti, P., Frank, D., Gričar, J., Gruber, A., Huang, J.-G., Jyske, T., Kašpar, J., King, G., Krause, C., Liang, E., Mäkinen, H., Morin, H., Nöjd, P., Oberhuber, W., Prislan, P., Rathgeber, C. B. K., Saracino, A., Swidrak, I., and Treml, V.: Pattern of xylem phenology in conifers of cold ecosystems at the Northern Hemisphere, Glob. Change Biol., 22, 3804-3813, https://doi.org/10.1111/gcb.13317, 2016.

Salminen, H. and Jalkanen, R.: Modelling the effect of temperature on height increment of Scots pine at high latitudes, Silva Fenn., 39, 497-508, https://doi.org/10.14214/sf.362, 2005.

Schiestl-Aalto, P., Kulmala, L., Mäkinen, H., Nikinmaa, E., and Mäkelä, A.: CASSIA - a dynamic model for predicting intra-annual sink demand and interannual growth variation in Scots pine, New Phytol., 206, 647-659, https://doi.org/10.1111/nph.13275, 2015.

Ťupek, B., Mäkipää, R., Heikkinen, J., Peltoniemi, M., Ukonmaanaho, L., Hokkanen, T., Nöjd, P., Nevalainen, S., Lindgren, M., and Lehtonen, A.: Foliar turnover rates in Finlandcomparing estimates from needle-cohort and litterfall-biomass methods, Boreal Environ. Res., 20, 283-304, 2015.

Vaganov, E. A., Hughes, M. K., and Shashkin, A. V.: Growth Dynamics of Conifer Tree Rings, Ecological Studies, Springer, Berlin and Heidelberg, 354 pp., 2006.

Zweifel, R., Haeni, M., Buchmann, N., and Eugster, W.: Are trees able to grow in periods of stem shrinkage?, New Phytol., 211, 839-849, https://doi.org/10.1111/nph.13995, 2016. 